\title{
Impurity State of Transition Group Elements in the Silicon Lattice in the Process of Their Interaction with Sulfur
}

\author{
Shaikrom Askarov $^{1}$, Sharipov Bashirulla ${ }^{1}$, Srazhev Solizhon ${ }^{2}$, Toshboev Tuchi ${ }^{2}$, Salieva Shokhista $^{1}$ \\ ${ }^{1}$ Department of Physics, Faculty of Mechanics, Tashkent State Technical University, Tashkent, Uzbekistan \\ ${ }^{2}$ Department of Condensed Matter Physics, Faculty of Physics, Samarqand State University, Samarqand, Uzbekistan
}

Email address:

bashirulla@mail.ru (S. Bashirulla)

To cite this article:

Shaikrom Askarov, Sharipov Bashirulla, Srazhev Solizhon, Toshboev Tuchi, Salieva Shokhista. Impurity State of Transition Group Elements in the Silicon Lattice in the Process of Their Interaction with Sulfur. American Journal of Physics and Applications.

Vol. 6, No. 3, 2018, pp. 76-79. doi: 10.11648/j.ajpa.20180603.12

Received: February 7, 2018; Accepted: March 21, 2018; Published: June 14, 2018

\begin{abstract}
On the basis of comparative analysis of electrical properties of silicon doped with sulfur and nickel respectively at temperature range of $1000-1250^{\circ} \mathrm{C}$ in $50^{\circ} \mathrm{C}$ increments and after their subsequent thermal annealing at temperature range of $400-950^{\circ} \mathrm{C}$ together with control samples of silicon doped with sulfur and nickel, it was revealed that impurity centers of sulfur and nickel do not interact with each other in the matrix of silicon. The absence of such interaction is possibly due to the fact that the electronic configuration of the impurity centers of nickel in the crystal lattice of silicon turns out to be in the filled $3 d^{10}$ state, which gives it the character of an inert gas. In view of the absence of interaction of sulfur and nickel in silicon, it is concluded that electrically neutral chemically bound complexes in silicon are formed between sulfur substitution centers and centers of transition metal atoms.
\end{abstract}

Keywords: Silicon, Electrically Neutral Chemically Bound Complexes, Impurity Centers, Sulfur, Nickel, Transition Metals

\section{Introduction}

It is well known $[1,2]$ that in silicon matrix, the impurity centers of sulfur that actively interact with impurity centers of transition metals tend to form electrically neutral chemically bound complexes. If, in the case of manganese atoms, its interaction with sulfur in silicon takes place directly in the process of diffusion doping, on the other hand, in the case of other transition metals, their interaction with sulfur occurs during subsequent annealing of silicon crystals previously diffusively doped with interacting impurities. In each case, there was established a certain effective temperature of annealing $\left(\mathrm{T}_{\text {eff }}\right)$ when practically all electroactive centers of both sulfur and transition metals, while participating in the formation of complexes, were found to be completely electrically neutralized and the crystals appeared to acquire parameters of the original silicon prior to doping. In this case, a clear correlation was established between $T_{\text {eff }}$ and the Gibbs thermodynamic energy of corresponding compounds in nature [2]. Electrically neutral chemically bound sulfur complexes with transition metals, as the results of [3] have shown, were thermally stable up to $T_{\text {eff. }}$ Shortterm annealing at $\mathrm{T}>\mathrm{T}_{\text {eff }}$ of silicon crystals preliminarily saturated with electrically neutral chemically bound complexes led to the decomposition of complexes into separate components, accompanied by a change in the electrical parameters of the material. Behavior of transition metals at given annealing temperatures in the crystal lattice of silicon is extremely unstable.

Thus, in the process of short-term annealing, they practically disintegrate into the centers of decay and transform into electrically neutral state while the observed change in the electrical parameters of the material is largely determined by the presence of electrically active impurity sulfur substitution centers, thus indicating that in the process of formation of complexes with transition metals, sulfur turns out to be in substitution state. However, the question of the position of the impurity centers of transition metals in the silicon lattice in the course of their interaction with sulfur remains unclear. 


\section{The Aim of the Study}

The present work is devoted to the investigation of the interaction of sulfur and nickel in silicon with the aim to clarify the state of transition metals in the silicon crystal lattice in the process of their interaction with impurity centers of sulfur. In contrast to other transition metals, nickel in silicon is characterized by sufficiently high solubility, reaching up to $5 \cdot 10^{17} \mathrm{~cm}^{-3}$. However, only a small part of nickel $(0.1 \%$ of the total concentration) forms solid substitution solution and shapes two acceptor levels in the forbidden band of silicon with energies of $E_{v}+0.2 \mathrm{eV}$ and $\mathrm{E}_{\mathrm{c}}-0.4 \mathrm{eV}$ [4], while the majority of nickel in silicon dissolves in the form of electrically neutral impurity clusters. [5]. The shape, size and nature of the location of impurity clusters of nickel in the volume of silicon depends on the rate of post-diffusion annealing and the temperature of subsequent additional treatments [6]. The nature of the change in the clusters suggests that, both during the doping process and during subsequent heat treatment, the impurity centers of nickel in the silicon crystal lattice are in the interstitial state. Therefore, during annealing, interstitial atoms of nickel, easily migrating through the crystal lattice of silicon, accumulate in various centers of decay.

Interstitial nickel clusters in silicon are in the filled $3 \mathrm{~d}^{10}$ state, as in accordance with the result of work [7], external Selectrons of transition metals in the interstitial state pass into the inner d-shell. The filled d-shell ensures that centers of nickel in silicon manifest the properties of inert gas. It follows that if electrically neutral chemically bound complexes in silicon are formed between the sulfur substitution centers and the centers of transition metals, then in the case of sulfur with nickel such complex formation is virtually absent.

\section{Experimental and Conclusions}

To figure out the presence or absence of the interaction of sulfur and nickel, the initial samples of single-crystal silicon of the KDB type (silicon doped with boron $p$-type) with a resistivity $\rho=10 \mathrm{Ohm} \cdot \mathrm{cm}$ grown by the Czochralski method with an active oxygen concentration of $5 \cdot 10^{17} \mathrm{~cm}^{-2}$ and $8 \times 3 \times 1$ $\mathrm{mm}^{3}$ were pre-diffusion doped with sulfur at $1250^{\circ} \mathrm{C}$ from the gas phase at a vapor pressure of the diffusing agent of $10^{5}$ $\mathrm{Pa}$ for 20 hours. After doping, we have obtained overcompensated samples of $\mathrm{n}-\mathrm{Si}<\mathrm{B}, \mathrm{S}>$ with $\rho=20$ $\mathrm{Ohm} \cdot \mathrm{cm}$. Then the samples of $\mathrm{Si}<\mathrm{B}, \mathrm{S}>$ were additionally doped with nickel from the sputtered metal layer in an argon atmosphere in the temperature range of $1000-1250^{\circ} \mathrm{C}$ in $50^{\circ} \mathrm{C}$ increments for one hour. For comparison, in each case, also control samples of $\mathrm{Si}<\mathrm{B}, \mathrm{S}>$ without nickel and samples of initial silicon with nickel $\mathrm{Si}<\mathrm{B}, \mathrm{Ni}>$ were annealed.
Investigation of the electrical parameters of the obtained samples showed that the parameters of $\mathrm{Si}<\mathrm{B}, \mathrm{S}, \mathrm{Ni}>$ samples irrespective of the annealing temperature are comparable with the parameters of the control samples $\mathrm{Si}<\mathrm{B}, \mathrm{S}>$ annealed under the same conditions. As the annealing temperature decreases, the specific electrical resistance of the overcompensated samples of $\mathrm{Si}<\mathrm{B}, \mathrm{S}, \mathrm{Ni}>$ and $\mathrm{Si}<\mathrm{B}, \mathrm{S}$, $>$ increases due to the partial decomposition of solid S-Si. The parameters of samples $\mathrm{Si}<\mathrm{B}, \mathrm{Ni}>$ irrespective of the annealing temperature were close to the parameters of the initial material. The weak influence of nickel doping on the electrical parameters of the material is associated with a low concentration of electrically active nickel atoms and the suppression of thermo-annealing defects in the doping process. The identity of parameters of $\mathrm{Si}<\mathrm{B}, \mathrm{S}, \mathrm{Ni}>$ samples and pilot samples $\mathrm{Si}<\mathrm{B}, \mathrm{S}>$ can be interpreted either by the absence of interaction between impurity centers of sulfur and nickel in silicon or by the instability of their complexes during high-temperature annealing.

To determine which of the above assumptions might be correct, the samples of $\mathrm{Si}<\mathrm{B}, \mathrm{S}, \mathrm{Ni}>, \mathrm{Si}<\mathrm{B}, \mathrm{S}>$ and $\mathrm{Si}<\mathrm{B}$, $\mathrm{Ni}>$ previously annealed at $1250^{\circ} \mathrm{C}$ were subsequently annealed in the temperature range of $400-950^{\circ} \mathrm{C}$ for various durations. The electric parameters of the samples after annealing are shown in Table 1 . The results in Table 1 prove that in the temperature range of $400-500^{\circ} \mathrm{C}$, as the annealing time increases, the resistivity of samples $\mathrm{Si}<\mathrm{B}, \mathrm{S}, \mathrm{Ni}>, \mathrm{Si}$ $<\mathrm{B}, \mathrm{S}>$ decreases, whereas the resistivity of the control samples of $\mathrm{Si}<\mathrm{B}, \mathrm{Ni}>$ increases as the duration of annealing increases, followed by inversion of the conductivity type to n-type and the decrease in the resistivity. The observed change in the parameters of samples is most likely due to the generation of thermally generated donors in the volume of the crystal. In favor of this assumption, one can attribute the fact that the maximum change in the parameters of the samples takes place at the temperature of $450{ }^{\circ} \mathrm{C}$, which corresponds to the temperature of the most intense generation of thermal donors in oxygen-containing silicon. However, it's worth mentioning that the concentration of generated thermal donors in $\mathrm{Si}<\mathrm{B}, \mathrm{S}, \mathrm{Ni}>$ and $\mathrm{Si}<\mathrm{B}, \mathrm{S}>$ samples in the temperature range of $400-500^{\circ} \mathrm{C}$ was slightly lower their concentration in $\mathrm{Si}<\mathrm{B}, \mathrm{Ni}>$ samples and the ingot wafer annealed at the same temperature range. With further increase in the annealing temperature up to $600^{\circ} \mathrm{C}$, the parameters of all samples remained practically unchanged. Further increase in the annealing temperature led to a gradual increase in the resistivity of the samples of $\mathrm{Si}<\mathrm{B}, \mathrm{S}, \mathrm{Ni}>$ and $\mathrm{Si}<\mathrm{B}, \mathrm{S}>$ as a function of annealing time, followed by the inversion of the conductivity type to p-type and the decrease in the resistivity level down to the parameters that the initial material manifested before doping. 
Table 1. Parameters of samples as a function of repetitive annealing.

\begin{tabular}{|c|c|c|c|c|c|c|c|}
\hline \multirow[b]{2}{*}{$\begin{array}{l}\text { Temp of annealing, } \\
t^{\circ} \mathrm{C}\end{array}$} & \multirow[b]{2}{*}{$\begin{array}{l}\text { Duration of } \\
\text { annealing }\end{array}$} & \multicolumn{2}{|l|}{$\mathrm{Si}<\mathbf{B}, \mathbf{S}, \mathbf{N i}>$} & \multicolumn{2}{|l|}{$\mathbf{S i}<\mathbf{B}, \mathbf{S}>$} & \multicolumn{2}{|l|}{$\mathrm{Si}<\mathbf{B}, \mathbf{N i}>$} \\
\hline & & $\begin{array}{l}\text { Type of } \\
\text { conductivity }\end{array}$ & $\rho=$ Ohm $\cdot \mathbf{c m}$ & $\begin{array}{l}\text { Type of } \\
\text { conductivity }\end{array}$ & $\rho=$ Ohm $\cdot \mathbf{c m}$ & $\begin{array}{l}\text { Type of } \\
\text { conductivity }\end{array}$ & $\rho=\mathbf{O h m} \cdot \mathbf{c m}$ \\
\hline \multirow[t]{2}{*}{1250} & 1 & $\mathrm{n}$ & 1.49 & $\mathrm{n}$ & 1.32 & $\mathrm{p}$ & 10.1 \\
\hline & 10 & $\mathrm{n}$ & 1.31 & $\mathrm{n}$ & 2.96 & $\mathrm{p}$ & 20.3 \\
\hline \multirow{3}{*}{400} & 30 & $\mathrm{n}$ & 0.81 & $\mathrm{n}$ & 1.83 & $\mathrm{p}$ & 47.4 \\
\hline & 75 & $\mathrm{n}$ & 0.7 & $\mathrm{n}$ & 1.18 & $\mathrm{p}$ & 210 \\
\hline & 100 & $\mathrm{n}$ & 0.5 & $\mathrm{n}$ & 0.9 & $\mathrm{p}$ & 3120 \\
\hline \multirow[t]{2}{*}{1250} & 1 & $\mathrm{n}$ & 4.8 & $\mathrm{n}$ & 8.22 & $\mathrm{p}$ & 10.1 \\
\hline & 10 & $\mathrm{n}$ & 2,21 & $\mathrm{n}$ & 4.2 & $\mathrm{n}$ & 2.66 \\
\hline \multirow{3}{*}{450} & 30 & $\mathrm{n}$ & 1.71 & $\mathrm{n}$ & 3.53 & $\mathrm{n}$ & 1.02 \\
\hline & 60 & $\mathrm{n}$ & 1.54 & $\mathrm{n}$ & 2.62 & $\mathrm{n}$ & 0.62 \\
\hline & 100 & $\mathrm{n}$ & 1.23 & $\mathrm{n}$ & 2.09 & $\mathrm{n}$ & 0.51 \\
\hline \multirow[t]{2}{*}{1250} & 1 & $\mathrm{n}$ & 2.9 & $\mathrm{n}$ & 3.1 & $\mathrm{p}$ & 10.6 \\
\hline & 10 & $\mathrm{n}$ & 2.52 & $\mathrm{n}$ & 2.83 & $\mathrm{p}$ & 12.4 \\
\hline \multirow{3}{*}{500} & 30 & $\mathrm{n}$ & 2.45 & $\mathrm{n}$ & 2.81 & $\mathrm{n}$ & 10.1 \\
\hline & 60 & $\mathrm{n}$ & 2.4 & $\mathrm{n}$ & 2.7 & $\mathrm{n}$ & 9.1 \\
\hline & 100 & $\mathrm{n}$ & 2.4 & $\mathrm{n}$ & 2.7 & $\mathrm{n}$ & 8.5 \\
\hline \multirow[t]{2}{*}{1250} & 1 & $\mathrm{n}$ & 8.21 & $\mathrm{n}$ & 8.34 & $\mathrm{p}$ & 10.1 \\
\hline & 10 & $\mathrm{n}$ & 4.61 & $\mathrm{n}$ & 5.81 & $\mathrm{p}$ & 10.3 \\
\hline \multirow{3}{*}{600} & 30 & $\mathrm{n}$ & 5.13 & $\mathrm{n}$ & 5.26 & $\mathrm{p}$ & 10.5 \\
\hline & 60 & $\mathrm{n}$ & 5.57 & $\mathrm{n}$ & 5.27 & $\mathrm{p}$ & 10.7 \\
\hline & 100 & $\mathrm{n}$ & 8.4 & $\mathrm{n}$ & 6.65 & $\mathrm{p}$ & 36 \\
\hline \multirow[t]{2}{*}{1250} & 1 & $\mathrm{n}$ & 4.0 & $\mathrm{n}$ & 6.1 & $\mathrm{p}$ & 10.1 \\
\hline & 10 & $\mathrm{n}$ & 2.62 & $\mathrm{n}$ & 4.25 & $\mathrm{p}$ & 10 \\
\hline 650 & 30 & $\mathrm{n}$ & 10.86 & $\mathrm{n}$ & 29.5 & $\mathrm{p}$ & 10 \\
\hline 030 & 60 & $\mathrm{p}$ & 34.8 & $\mathrm{p}$ & 33.1 & $\mathrm{p}$ & 15 \\
\hline & 100 & $\mathrm{p}$ & 12.1 & $\mathrm{p}$ & 11 & $\mathrm{p}$ & 21 \\
\hline 1250 & 1 & $\mathrm{n}$ & 5.76 & $\mathrm{n}$ & 5.12 & $\mathrm{p}$ & 10.1 \\
\hline & 10 & $\mathrm{n}$ & 6.17 & $\mathrm{n}$ & 6.35 & $\mathrm{p}$ & 10.1 \\
\hline 700 & 20 & $\mathrm{n}$ & 16.9 & $\mathrm{n}$ & 20.2 & $\mathrm{p}$ & 11.5 \\
\hline & 30 & $\mathrm{p}$ & 10 & $\mathrm{p}$ & 11,2 & $\mathrm{p}$ & 14.7 \\
\hline 1250 & 1 & $\mathrm{n}$ & 3.9 & $\mathrm{n}$ & 4.1 & $\mathrm{p}$ & 10.2 \\
\hline & 5 & $\mathrm{n}$ & 5.1 & $\mathrm{n}$ & 5.7 & $\mathrm{p}$ & 10.1 \\
\hline 725 & 15 & $\mathrm{n}$ & 21.1 & $\mathrm{n}$ & 23.7 & $\mathrm{p}$ & 10.1 \\
\hline & 25 & $\mathrm{p}$ & 10.7 & $\mathrm{p}$ & 10.3 & $\mathrm{p}$ & 10.1 \\
\hline 1250 & 1 & $\mathrm{n}$ & 7 & $\mathrm{n}$ & 9.1 & $\mathrm{p}$ & 10.3 \\
\hline & 5 & $\mathrm{n}$ & 6.5 & $\mathrm{n}$ & 6,7 & $\mathrm{p}$ & 10.1 \\
\hline 750 & 10 & $\mathrm{n}$ & 12.2 & $\mathrm{n}$ & 12,3 & $\mathrm{p}$ & 11.1 \\
\hline & 15 & $\mathrm{p}$ & 11.26 & $\mathrm{p}$ & 10,3 & $\mathrm{p}$ & 14.0 \\
\hline 1250 & 1 & $\mathrm{n}$ & 4.3 & $\mathrm{n}$ & 4,4 & $\mathrm{p}$ & 10.2 \\
\hline & 1 & $\mathrm{n}$ & 4.0 & $\mathrm{n}$ & 4,1 & $\mathrm{p}$ & 10.2 \\
\hline 775 & 3 & $\mathrm{n}$ & 210 & $\mathrm{n}$ & 240 & $\mathrm{p}$ & 10.1 \\
\hline & 5 & $\mathrm{p}$ & 12.1 & $\mathrm{p}$ & 11,8 & $\mathrm{p}$ & 10.1 \\
\hline 1250 & 1 & $\mathrm{n}$ & 3.14 & $\mathrm{n}$ & 5,1 & $\mathrm{p}$ & 10.32 \\
\hline & 0.5 & $\mathrm{n}$ & 2 & $\mathrm{n}$ & 2,64 & $\mathrm{p}$ & 10.4 \\
\hline 800 & 1 & $\mathrm{n}$ & 2.21 & $\mathrm{n}$ & 3,81 & $\mathrm{p}$ & 10.5 \\
\hline 000 & 2 & $\mathrm{n}$ & 6.15 & $\mathrm{n}$ & 6,9 & $\mathrm{p}$ & 11.1 \\
\hline & 3 & $\mathrm{p}$ & 11.7 & $\mathrm{p}$ & 11,6 & $\mathrm{p}$ & 12.4 \\
\hline 1250 & 1 & $\mathrm{n}$ & 4.1 & $\mathrm{n}$ & 4,7 & $\mathrm{p}$ & 10.5 \\
\hline & 0.5 & $\mathrm{n}$ & 2.7 & $\mathrm{n}$ & 2,9 & $\mathrm{p}$ & 10.4 \\
\hline 825 & 1 & $\mathrm{n}$ & 7.5 & $\mathrm{n}$ & 8,1 & $\mathrm{p}$ & 10.2 \\
\hline & 1.5 & $\mathrm{p}$ & 310 & $\mathrm{p}$ & 281 & $\mathrm{p}$ & 10.1 \\
\hline & 2 & $\mathrm{p}$ & 11.7 & $\mathrm{p}$ & 11,0 & $\mathrm{p}$ & 10.1 \\
\hline 1250 & 1 & $\mathrm{n}$ & 5.4 & $\mathrm{n}$ & 4,24 & $\mathrm{p}$ & 10.1 \\
\hline 850 & 0.5 & $\mathrm{p}$ & 111 & $\mathrm{p}$ & 150 & $\mathrm{p}$ & 10.1 \\
\hline 030 & 1 & $\mathrm{p}$ & 12 & $\mathrm{p}$ & 11,1 & $\mathrm{p}$ & 10.2 \\
\hline 1250 & 1 & $\mathrm{n}$ & 4.7 & $\mathrm{n}$ & 4,4 & $\mathrm{p}$ & 10.1 \\
\hline 875 & 0.5 & $\mathrm{p}$ & 55.1 & $\mathrm{p}$ & 60,2 & $\mathrm{p}$ & 10.1 \\
\hline $8 / 2$ & 1 & $\mathrm{p}$ & 10.9 & $\mathrm{p}$ & 11,0 & $\mathrm{p}$ & 10.1 \\
\hline 1250 & 1 & $\mathrm{n}$ & 2.29 & $\mathrm{n}$ & 2,7 & $\mathrm{p}$ & 10.1 \\
\hline 000 & 0.5 & $\mathrm{p}$ & 34.17 & $\mathrm{p}$ & 32,1 & $\mathrm{p}$ & 10.1 \\
\hline 900 & 1 & $\mathrm{p}$ & 10.5 & $\mathrm{p}$ & 10,3 & $\mathrm{p}$ & 10.1 \\
\hline
\end{tabular}

With the increase in the annealing temperature at which the samples of $\mathrm{Si}<\mathrm{B}, \mathrm{S}, \mathrm{Ni}>$ and $\mathrm{Si}<\mathrm{B}, \mathrm{S}>$ were restored, the parameters of the initial material were reduced. It should be noted that in most cases in the initial stage of heat 
treatment in the temperature range of $600-950{ }^{\circ} \mathrm{C}$ the resistivity of the samples of $\mathrm{Si}<\mathrm{B}, \mathrm{S}, \mathrm{Ni}>$ and $\mathrm{Si}<\mathrm{B}, \mathrm{S}>$ somewhat reduced. The observed decrease in the resistivity of $\mathrm{Si}<\mathrm{B}, \mathrm{S}, \mathrm{Ni}>$ and $\mathrm{Si}<\mathrm{B}, \mathrm{S}>$ samples is not due to the generation of thermal donors since in the temperature range of $600-800^{\circ} \mathrm{C}$ there occurs decomposition of thermal donors generated in oxygen-containing silicon in the temperature range of $350-600^{\circ} \mathrm{C}$.

Further changes in the parameters of the samples after a preliminary reduction in resistivity value may be associated with the decomposition of a solid solution of Si- S. Despite careful studies at an increment of $25^{\circ} \mathrm{C}$ in the temperature range $600-950^{\circ} \mathrm{C}$, we were not able to detect a temperature interval at which the nature of the change in the electrical parameters of the samples of $\mathrm{Si}<\mathrm{B}, \mathrm{S}, \mathrm{Ni}>$ would differ significantly from the parameters of the control samples $\mathrm{Si}$ $<\mathrm{B}, \mathrm{S}>$. Such a change in the parameters of the samples testifies to the lack of interaction between the impurity centres of sulfur and nickel in silicon both during diffusion doping and during subsequent heat treatment in the temperature range $400-950^{\circ} \mathrm{C}$.

The above stems from the fact that if they hypothetically interacted with each other, then, as in the case of the interaction of sulfur with other transition metals, during subsequent heat treatments near the $T_{\text {eff }}$ temperature, we would have witnessed a sharp change in the parameters of the $\mathrm{Si}<\mathrm{B}, \mathrm{S}, \mathrm{Ni}>$ in compare to the parameters of the control samples $\mathrm{Si}<\mathrm{B}, \mathrm{S}>$ in the interval up to the restoration of the $\mathrm{T}=\mathrm{T}_{\text {eff }}$ parameters of the initial material with subsequent increase in the resistivity of the samples at $\mathrm{T}>\mathrm{T}_{\text {eff }}$.

In a word, the nature of the change in the parameters of $\mathrm{Si}$ $<\mathrm{B}, \mathrm{S}, \mathrm{Ni}>$, unlike of the control samples $\mathrm{Si}<\mathrm{B}, \mathrm{S}>$, would have had non-monotonically nature as a function of the annealing temperature. Meanwhile, monotonically nature of the change in the parameters of silicon samples with sulfur and one of the transition metals is due to the fact that the sulfur substitution centers in silicon having formed $s p^{3}$-type hybrid covalent bond with four nearby silicon atoms would have had two extra unbounded electrons whereas the presence of these two unbounded sulfur electrons in silicon cause occurrence of two donor centers with energies $E_{c}-0.28$ and $\mathrm{E}_{\mathrm{c}}-0.37 \mathrm{eV}$ [8-10].

On the other hand, these extra unbonded sulfur electrons can stimulate a bond with two centers of transition metals through free $d$-orbits. In this case, a quasi-molecule type-Si $\mathrm{i}_{4}$ $\mathrm{SM}_{2}$ like $\mathrm{SF}_{6}$ molecules would appear. However, nickel centers in silicon, have d-orbital that are completely filled with electrons $\left(3 \mathrm{~d}^{10}\right)$ state, which gives them the character of an inert gas. In order to better understand how the presence of such condition affects the behaviour of nickel in silicon, we briefly discuss the known experimental results [4-6]:

1. nickel diffuses in silicon by a dissociative mechanism. Unlike other transition metals, nickel is characterized in silicon by an abnormally high diffusion coefficient $(\sim$ $\left.5 \cdot 10^{-5} \mathrm{~cm}^{2} / \mathrm{sec}\right)$ and solubility $\left(\sim 5 \cdot 10^{17} \mathrm{~cm}^{-3}\right)$. In this case, both the diffusion coefficient and the solubility of nickel do not depend on the concentration of the initial impurities, the dislocation density, and also the rate after the diffusion cooling, and is mainly determined by temperature of diffusion annealing;

2. despite high solubility, only an insignificant share ( $\left.5 \cdot 10^{14} \mathrm{~cm}^{-3}\right)$ of nickel impurity centers in silicon are electrically active. The majority of them dissolve in the form of electrically neutral clusters. The density and size of the clusters significantly depended on the rate of diffusion cooling and with the growth of the latter $(\sim 1$ $\mathrm{deg} / \mathrm{sec}$ ) the influence of dislocations on the structure of nickel deposition in silicon was revealed. A particularly strong influence of dislocations on the structure of nickel deposition was observed in crystals subjected to diffusion heat treatment in the range of $450-800^{\circ} \mathrm{C}$. In this case clusters were rearranged into more ordered states and acquired the form of linear chains.

Analyzing the above features of the behaviour of nickel in silicon, we can ascertain the fact that the nickel impurity centers in the process of high-temperature diffusion annealing practically do not interact with various defects of the crystal lattice and the cluster is formed in the process after diffusion cooling due to the decomposition of the "silicon-nickel" solid solution.

The absence of interaction between impurity centers of sulfur and nickel in silicon suggests that in the process of interaction with sulfur substitution centers, transition metals are likely to be in interstitial locations. In this case, the sulfur substitution center, in addition to the four covalent bonds with nearby silicon atoms, chemically binds to two impurity centers of transition metals in interstitial state.

\section{References}

[1] MK Bakhadyrkhanov, Sh. I. Askarov, N. Norkulov, FIT, 21.1456 (1987).

[2] M. K. Bakhadirxanov, Sh. I. Askarov, N. Norkulov, Phus. Stat. Sol. (A), 142.339 (1994).

[3] M. K. Bahadyrhanov, Sh. I. Askarov, N. Norkulov, A. Hamidov, Heorganicheskiematerialy, 32, 15 (1996).

[4] M. Yoshida, K. Saito, Appl, Phys., Japan, 6,573 (1967).

[5] M. K. Bahadyrhanov, S. Zaynobidinov, A. T. Teshaboev, M. A. Hodzhaeva, FTP, 10.1001 (1976).

[6] M. K. Bahadyrkhanov, S. Zainobidinov, FIT, 12,683 (1978).

[7] G. Wudbury, J. Ludwig, Sat. articles: Electron spin resonance in semiconductors. IL, M. (1968).

[8] M. Steger, A. Yang, MLWThewalt, M. Kardona, H. Riemann, NVAbrosimov, MFChurbanov, AVGusev, ADBulanov, IDKovalev, AKKalliteevskii, ONGodisov, P. Becker, HJPohe, EEHaller, JWAger, III. Phus. Rev. B, 80,115204 (2009).

[9] Yu. A. Astrov, L. M. Portsel, A. L. Lodygin, V. B. Shuman Semicond. Sci. Tehnol. 26,055.021 (2011).

[10] V. B. Shuman, A. A. Mahova, Yu. Ayu Astrov, Ayu My Ivanov, A, N. Lodygin, FTP, 46.993, (2012). 